Review Article

\title{
Pros and Cons of Aspirin Prophylaxis for Prevention of Cardiovascular Events in Kidney Transplantation and Review of Evidence
}

\author{
Muhammad Abdul Mabood Khalil (D), ${ }^{1}$ Muhammad Shahab Ud Din Khalil, ${ }^{2}$ \\ Said Sayed Ahmed Khamis, ${ }^{3}$ Sartaj Alam $\left(\mathbb{D},{ }^{4}\right.$ Rajendra Govindrao Daiwajna, ${ }^{1}$ \\ Ahmed Suleman Rajput, ${ }^{1}$ Mohammed M. Alhaji, ${ }^{5}$ Vui Heng Chong $\mathbb{D}^{6},{ }^{6}$ and Jackson Tan $\mathbb{D}^{7}$ \\ ${ }^{1}$ RIPAS Hospital, Bandar Seri Begawan BA1710, Brunei Darussalam \\ ${ }^{2}$ Department of Cardiology, Lady Reading Hospital, Postal Code, 25000, Peshawar, Pakistan \\ ${ }^{3}$ Faculty of Medicine, Menoufia University, Egypt \\ ${ }^{4}$ Department of Nephrology, Lady Reading Hospital, Postal Code 25000, Peshawar, Pakistan \\ ${ }^{5}$ PAPRSB Institute of Health Sciences, Universiti Brunei Darussalam, Brunei Darussalam \\ ${ }^{6}$ Department of Medicine, RIPAS Hospital, Bandar Seri Begawan BA1710, Brunei Darussalam \\ ${ }^{7}$ Department of Renal Medicine, RIPAS Hospital, Bandar Seri Begawan BA1710, Brunei Darussalam
}

Correspondence should be addressed to Muhammad Abdul Mabood Khalil; doctorkhalil1975@hotmail.com

Received 17 January 2019; Accepted 28 April 2019; Published 16 May 2019

Academic Editor: William C. Cho

Copyright (C) 2019 Muhammad Abdul Mabood Khalil et al. This is an open access article distributed under the Creative Commons Attribution License, which permits unrestricted use, distribution, and reproduction in any medium, provided the original work is properly cited.

Kidney transplant recipients have traditional and nontraditional risk factors which can lead to coronary artery disease and sudden death with a functional graft loss. Aspirin has been used traditionally for prevention of cardiovascular and cerebrovascular accidents. It has beneficial effects in secondary prevention of cardiovascular events in general population. Its use for primary prophylaxis is still disputed. Bleeding and theoretical risk of nephrotoxicity are the major concerns about its use. The data on aspirin in kidney transplant population is sparse. This review will focus on various pros and cons of aspirin use for prevention of cardiovascular events in kidney transplant recipients and a way forward.

\section{Introduction}

Cardiovascular disease is the leading cause of morbidity and mortality in kidney transplant recipients (KTR). The age of KTR is increasing over time from 35-45 years in 1988 to $50-64$ in 2012 [1]. The increasing age is associated with more accumulation of comorbidities such as diabetes, hypertension, dyslipidemia, and atherosclerosis. The incidence of myocardial infarction after kidney transplantation is 4.7-11.1\% [2]. Cardiovascular disease is the leading cause of functional graft loss and it accounts for $30 \%$ of overall mortality [3]. Aspirin is widely used for prevention of cardiovascular and cerebrovascular events in the general population. In this review, we will discuss the use of aspirin in primary and secondary prophylaxis for cardiovascular events and its pros and cons in KTR.

\section{Mechanism of Action of Aspirin}

Aspirin inhibits platelet function by acetylation of the platelet cyclooxygenase (COX) [3]. Aspirin is an approximately 150to 200-fold more potent inhibitor (constitutive) isoform of the platelet enzyme (COX-1) than the (inducible) isoform (COX-2) which is expressed by cytokines, inflammatory stimuli, and some growth factors. As a result, the dose for inflammatory conditions is remarkably high as compared to antiplatelet activity which is around $100 \mathrm{mg} /$ day [4]. 


\section{Concerns about Aspirin Use}

Nonsteroidal anti-inflammatory medications (NSAIDs) are well known for nephrotoxicity, gastritis, and bleeding. Aspirin, being a NSAID, can also potentially cause these complications. Nephrotoxicity in the setting of kidney transplantation is even more important as the recipient only has one functional kidney. We will review these potential complications in this section.

3.1. Nephrotoxicity of Aspirin. Previous studies have shown conflicting results about the use of aspirin and the risk of chronic kidney diseases. Some earlier studies have shown that the use of aspirin is associated with chronic kidney disease [57]. Some studies implicated acetaminophen and phenacetin in the development of CKD but not aspirin $[8,9]$. Other studies in healthy people did not find any association between aspirin and nephrotoxicity. A study in healthy physicians did not find any correlation between aspirin and other nonsteroidal anti-inflammatory medications and the development of chronic kidney disease [10-12]. Similarly a study on healthy nurses failed to show any association between NSAIDs and the development of chronic kidney disease [13]. Various studies were done on aspirin and its effects on proteinuria and glomerular filtration rates. Multiple randomized controlled trials on aspirin in diabetic patients were not associated with decrement in GFR or albuminuria [14-16]. Another randomized controlled trial on diabetic patients showed significant reduction of proteinuria in 24 hours by using aspirin-dipyridamole [17]. In view of these studies, one can assume that aspirin has negligible nephrotoxicity.

Aspirin has been used for prevention of renal vein thrombosis in KTR. In the majority of these studies, no adverse outcome was observed in terms of graft dysfunction. Aspirin has been shown to improve graft survival in a retrospective study and a meta-analysis $[18,19]$. In other studies, the use of aspirin did not improve graft survival but at the same time did not have any adverse effect on graft function. Ali $\mathrm{H}$ et al. did not find any beneficial effects of aspirin on improving graft survival and found that it has a negligible effect on kidney allograft function as compared to those who were not on aspirin [20]. In a similar study, aspirin reduced the rate of early graft thrombosis but did not improve renal function or graft survival. However, a trend of lower rate of chronic allograft nephropathy was observed in this study [21]. One can assume from all these studies that the risk of nephrotoxicity with aspirin is insignificant. The summary of these studies has been shown in Table 1.

3.2. Bleeding. Low-dose aspirin has been associated with increased risk of bleeding in the general population [41, 42]. Gastrointestinal bleeding [43, 44], intracranial bleeding [44], and postoperative surgical site hemorrhage are common in KTR [44]. Cumulative incidence of hospitalization for gastrointestinal bleeding in KTR is 334 events per 100,000 patient years. The incidence of major nontraumatic bleeding has been reported as $3.5 \%$ in KTR as compared to $0.4 \%$ in normal population [44]. The GI endoscopic procedures were 15-fold higher than in the general population [44]. The data on bleeding due to low-dose aspirin and its relation with bleeding in KTR is limited [19]. Our literature review found few studies on the prevention of renal vein thrombosis and allograft biopsies. These studies reported mixed results for the risk of bleeding with aspirin. Robertson et al. found major bleeding in $2.7 \%$ of cases in a retrospective analysis for the use of aspirin in renal vein thrombosis [22]. In another study on prevention of renal vein thrombosis, postbiopsy macroscopic hematuria was 9 percent in the aspirin treated group and 7 percent in the control group [22]. Hachem et al. in a case control study found no difference at postoperative surgical site hemorrhage [23]. In a retrospective analysis, KTR who were on dual antiplatelet because of coronary artery disease have more blood transfusion as compared to those who were not on dual antiplatelet (30.3\% vs. $15.7 \%)$ [24]. Requirements for transfusions was also reported in another retrospective study in patients who were on dual antiplatelet. However, on multivariate logistical regression analysis it was not significant [25]. Aspirin in combination with anticoagulants can lead to significant bleeding [26]. There are couple of case series on allograft biopsies and risk of bleeding due to aspirin. Atwell et al. studied the incidence of bleeding after 15,181 percutaneous biopsies of various organs (including kidney) and its association with aspirin. They found no difference in major bleeding, if aspirin was taken within 10 days before kidney biopsy [27]. Baffour et al. [28] analyzed 6,700 renal allograft biopsies and compared various durations of aspirin exposure in KTR and their impact on bleeding. They compared no aspirin exposure in 10 days and exposure of aspirin in 8-10, 4-7, and 0-3 days. They found that the risk of bleeding was more with aspirin exposure within 0 3 days. Interestingly Lee et al. in their retrospective analysis of kidney biopsies (including allografts) showed no major bleeding in patients on aspirin [29]. The data on aspirin and risk of gastrointestinal and intracranial bleeding is sparse. Keeping in mind the risk of aspirin related gastrointestinal bleeding in the general population and 15-fold higher chance of gastrointestinal endoscopic procedure in KTR, this risk cannot be ignored. It is important to evaluate the risk of bleeding in KTR, who are being considered for aspirin prophylaxis. Table 2 shows a summary of all these studies.

\section{Aspirin Prophylaxis}

4.1. Primary Prophylaxis in KTR. Various models have been used to predict cardiovascular events in the general population. These include the Framingham Risk Score, the Reynolds Risk Score, the Prospective Cardiovascular Münster Heart Study (PROCAM), the Systematic Coronary Risk Evaluation system (SCORE), and the QRISK 1 and 2 [45-50]. Recently, U.S. Preventive Task Force has published guidelines for predicting cardiovascular risk using pool cohort equation and primary prophylaxis with aspirin [51]. Risk factors for cardiovascular events in KTR are different from those in the general population. Nontraditional factors play an important role in causing cardiovascular events in this population. These factors include albuminuria, anemia, and graft rejection [52], time on dialysis before transplantation [53], immunosuppressive medications [54], and elevated homocystine [55]. 


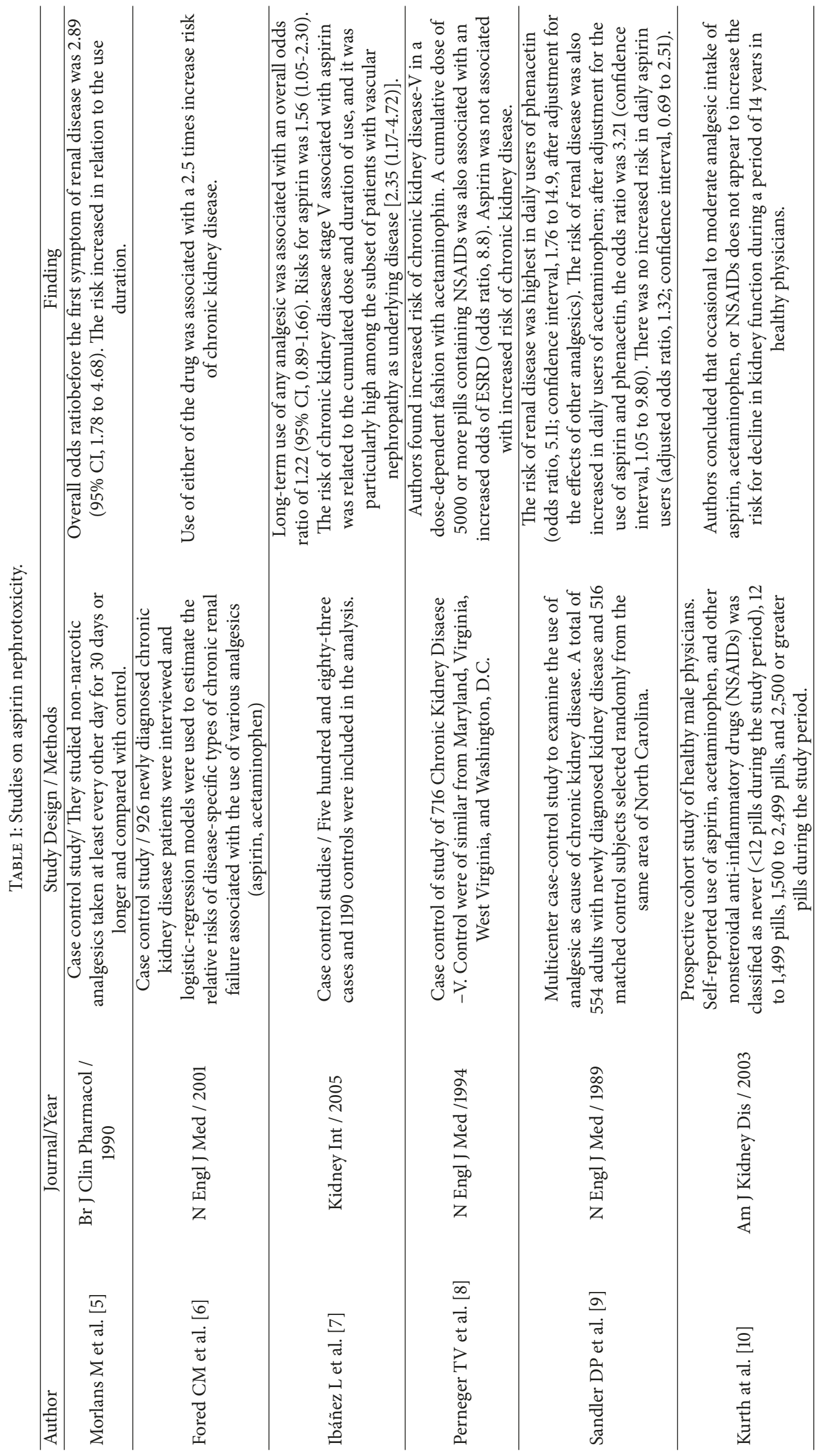




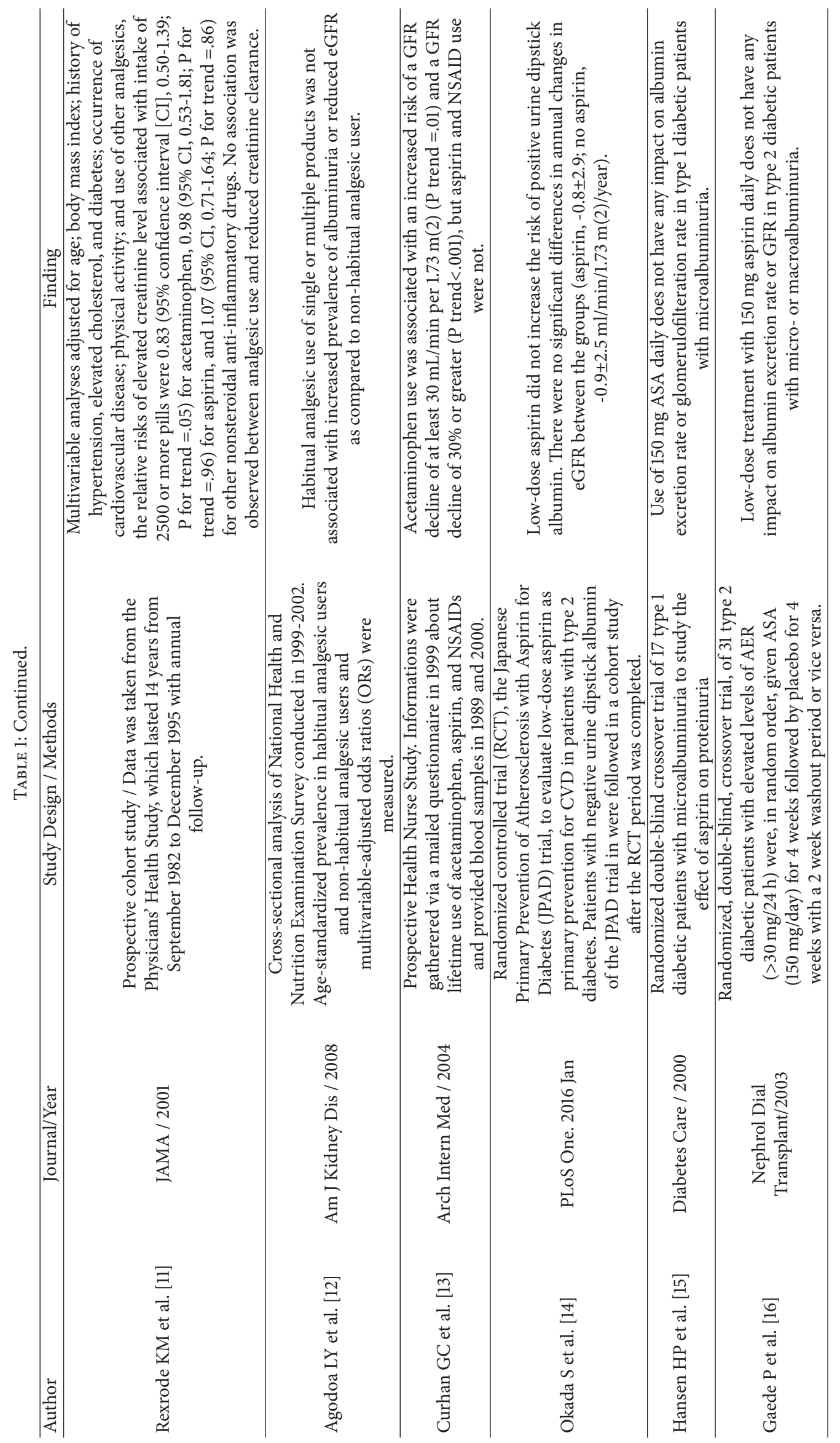




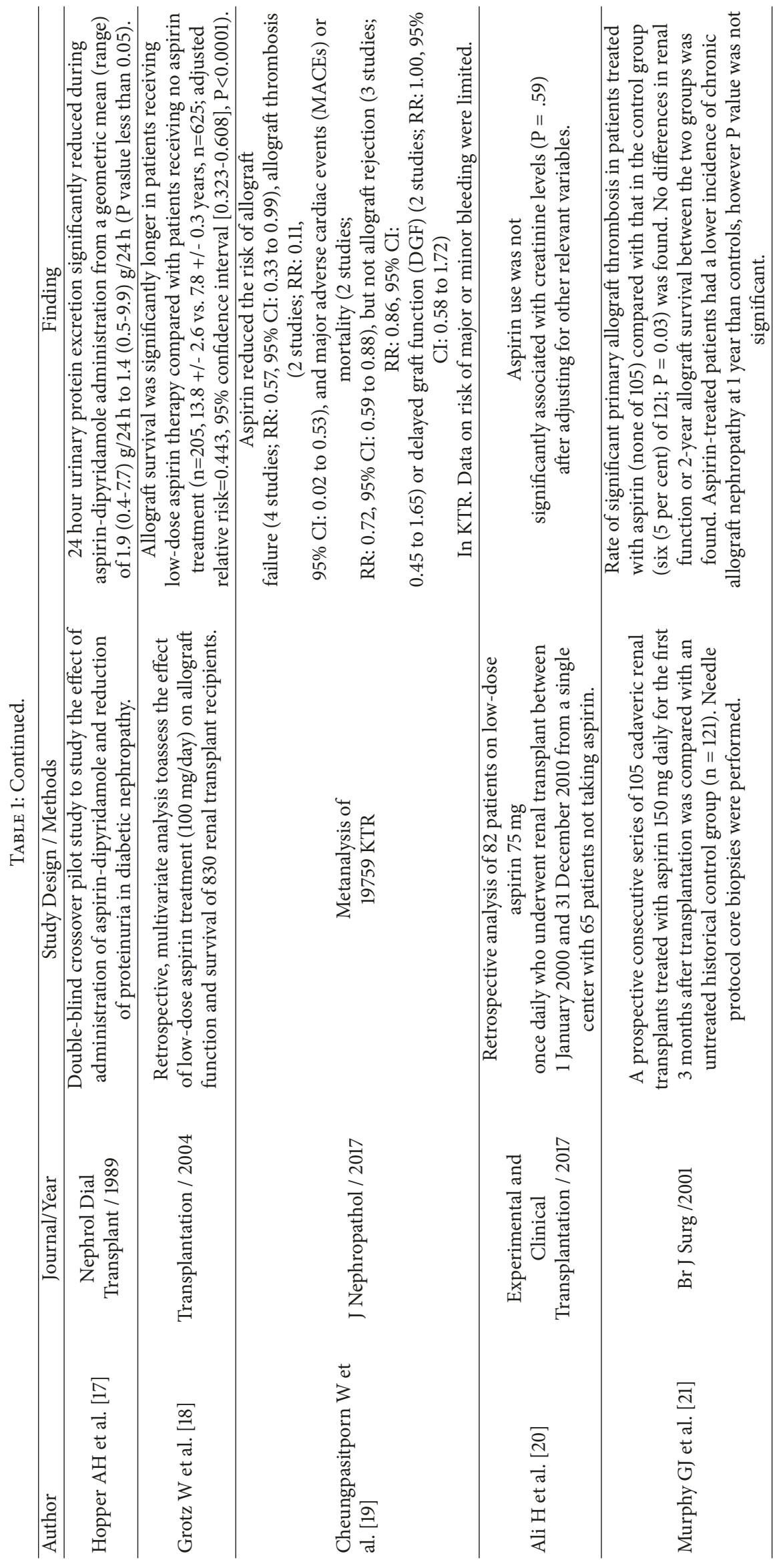




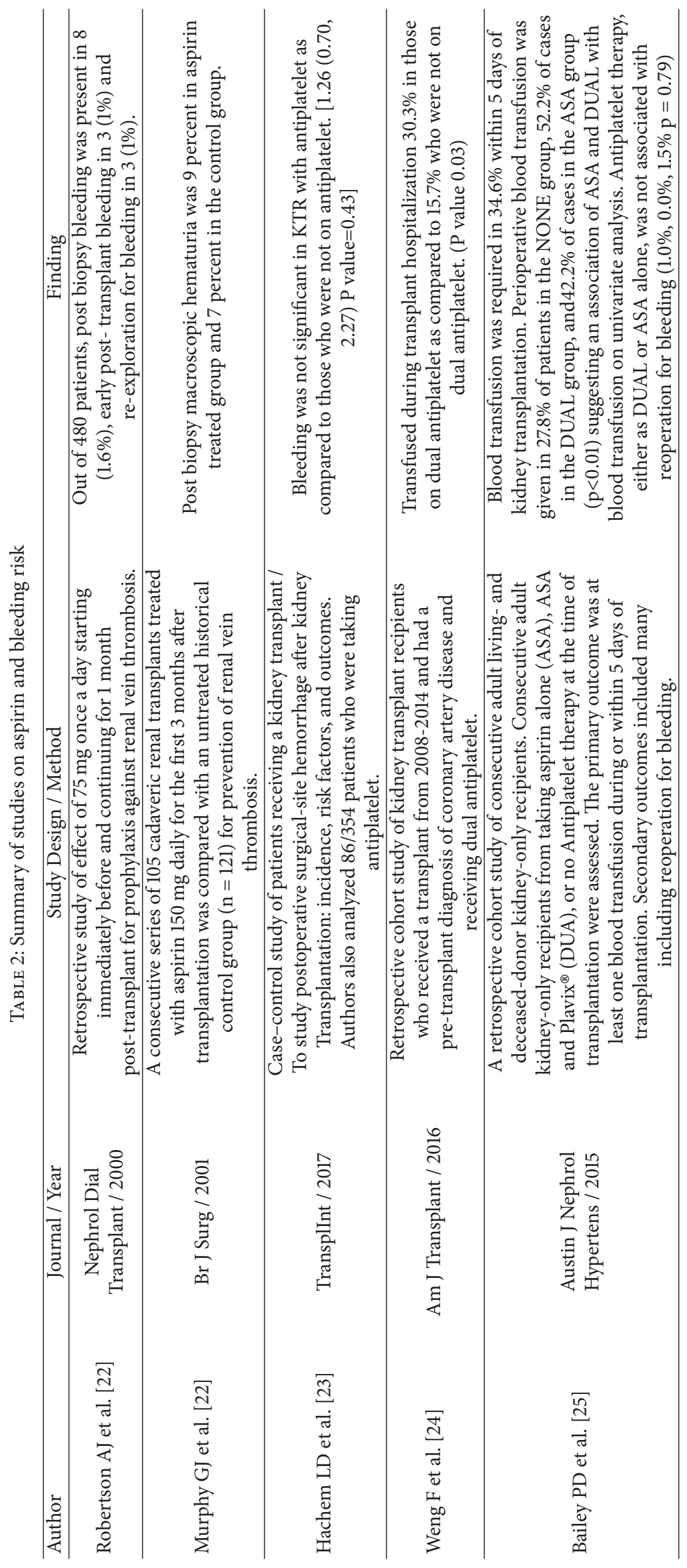




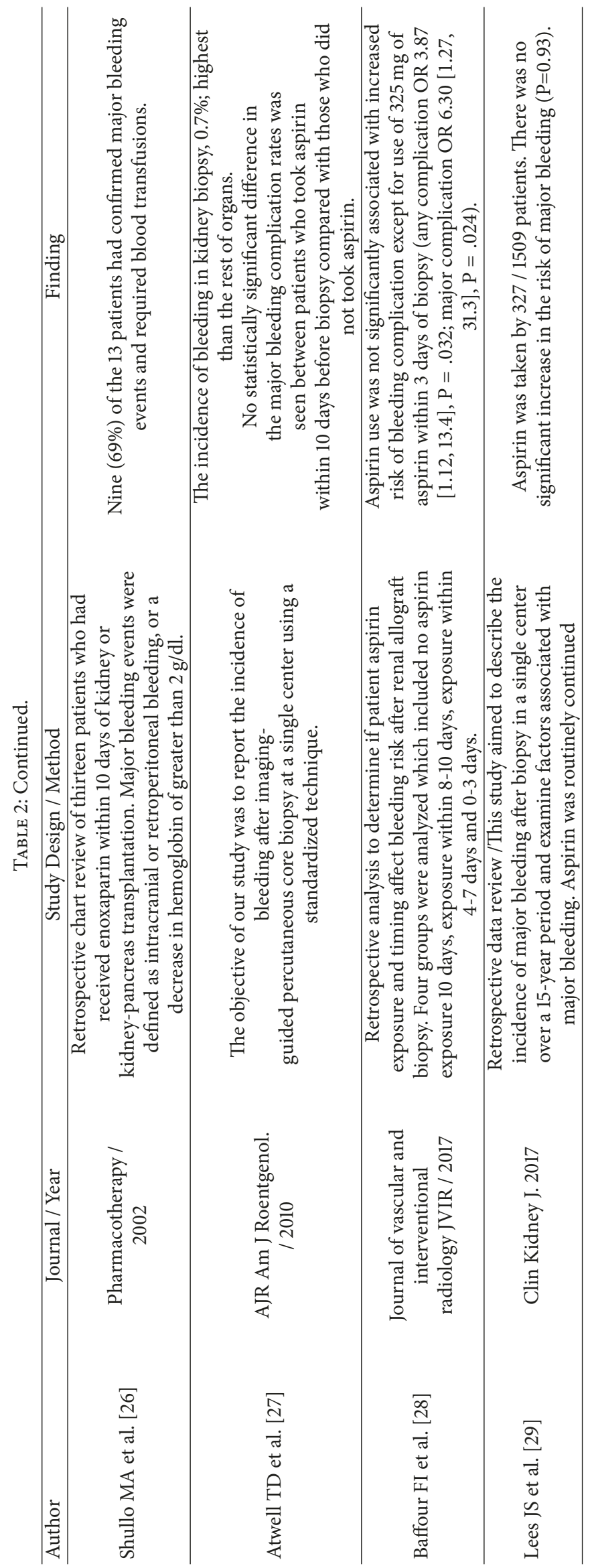


These factors are usually not taken into account in various risk scores. The Framingham Risk Model underestimated cardiovascular events in KTR $[56,57]$. The American Heart Association (ACC/AHA) pooled cohort equations to predict 10 -year risk have not been validated in KTR to predict cardiovascular risk in this specific group of patients. Recently Heleniak $\mathrm{Z}$ et al. retrospectively analyzed various scores for cardiovascular risk prediction in KTR and found that the QRISK2 and Pol-SCORE scales seem to be the most predictive in assessing $\mathrm{CV}$ risk in KTR as compared to PROCAM and Framingham [58]. Soveri et al. used a 7-year risk model for KTR [59]. They predicted major cardiovascular events using a seven-variable model including age, previous coronary heart disease, diabetes, low-density lipoprotein, creatinine, number of transplants, and smoking [59]. A systematic review analyzed metrics of model performance and evaluation of bias in KTR and found room for improvement for accurate prediction of cardiovascular risk [60]

Evidence for aspirin use in KTR for primary prophylaxis is still lacking. Guidelines differ in the recommendation of aspirin use in primary prophylaxis. The United States Preventive Services Task Force recommends low-dose aspirin for the primary prevention of cardiovascular disease in adults aged 50-59 years who have a $10 \%$ or greater 10 year CVD risk [51]. Candidates for aspirin should not be at increased risk of bleeding, life expectancy should be greater than at least 10 years, and they should be willing to take it regularly. For those aged 60-69, the decision is on an individual basis. If the 10 -year CVD risk is greater than $10 \%$ and there is no risk of bleeding, then low-dose aspirin should be considered. The evidence for low-dose aspirin prophylaxis in patients younger than 50 years old or older than 70 years is not enough, and the pros and cons of its use are not known. Task Force recommended American Heart Association recommendation pooled cohort equations to predict hard atherosclerotic cardiovascular events (defined as nonfatal myocardial infarction, coronary heart disease death, and fatal or nonfatal stroke) [61]. Calculators assess the risk using various variables including age, gender, race, total cholesterol, HDL-cholesterol, systolic blood pressure, diastolic blood pressure, treatment for high blood pressure, diabetes, and smoking [61]. Unfortunately, there is no validation of ACC/AHA pooled cohort equation in KTR. The American Diabetic Association recommends that $75-162 \mathrm{mg} /$ day may be considered as a primary prevention strategy in those with type 1 or type 2 diabetes who are at increased cardiovascular risk. This includes most men and women with diabetes aged $\geq 50$ years who have at least one additional major risk factor (family history of premature atherosclerotic cardiovascular disease, hypertension, dyslipidemia, smoking, or albuminuria) and are not at increased risk of bleeding [62]. In contrast, the Canadian Cardiovascular Society guideline does not recommend primary prophylaxis with aspirin [63]. Similarly in the UK, aspirin is not recommended for primary prevention of cardiovascular events [64]. No randomized trials to date have evaluated the primary use of aspirin for primary prophylaxis in dialysis or transplant patients. As a result firm recommendations cannot be made. Because of lack of evidence, the use of aspirin in the setting of renal dysfunction has been minimal. Review of National Cardiovascular Data ACTION (Acute Coronary Treatment and Intervention Outcomes Network) in ST elevated myocardial infarction and non-ST elevated myocardial infarction showed lesser use of aspirin with worsening CKD [65]. Similarly, Berger and his colleagues found that end stage renal disease (ESRD) patients with myocardial infarction were less likely to receive aspirin, beta blocker, or angiotensin converting enzyme inhibitor as compared to patients without ESRD. The benefit of these therapies on 30-day mortality was similar among ESRD patients and non-ESRD patients [66]. A recent trial on hypertension (Hypertension Optimal Treatment or HOT) [67] randomly assigned patients with diastolic hypertension to aspirin $75 \mathrm{mg}$ or placebo. Statistical analysis detected a $66 \%$ reduction ( $95 \%$ CI, 33 to 83 ) in major adverse cardiovascular events and a $49 \%$ reduction (95\% CI, 6 to 73) in mortality, respectively, among the subgroup with baseline eGFR $45 \mathrm{~mL} / \mathrm{min}$. Use of aspirin in chronic kidney disease patients reduced in patients' mortality to $64.3-80 \%$ across all quartiles of creatinine clearance[68]. A retrospective analysis of acute coronary syndrome patients showed that use of aspirin was associated with a decreased rate of ST-segment elevation myocardial infarction in patients with GFR $60 \mathrm{mls} / \mathrm{min}$ [69]. There are few retrospective studies and a meta-analysis in KTR, where aspirin prophylaxis was used for the prevention of renal vein thrombosis [18-20]. However, not all of these studies looked at the cardiovascular mortality. A meta-analysis found that aspirin reduces major adverse cardiovascular events or mortality (2 studies; RR: 0.72 , 95\% CI: 0.59 to 0.88 ) in KTR [19]. However, there was no randomized control trial looking for major adverse cardiovascular events in this meta-analysis. Post hoc analysis of the FAVORIT (Folic Acid for Vascular Reduction in Transplantation) study on aspirin failed to show reduction in cardiovascular events [70]. Kidney Disease Improving Global Outcomes (KDIGO) 2009, practice guidelines for prevention of cardiovascular events in kidney transplant recipients with diabetes or cardiovascular disease, suggest use of low-dose aspirin based on very poor quality of evidence [71]. Recently two randomized control trials were published. ASCEND (a Study of Cardiovascular Events in Diabetes) was a randomized trial to assess the efficacy and safety of enteric-coated aspirin at a dose of $100 \mathrm{mg}$ daily vs. placebo, in diabetics without any cardiovascular disease at trial entry [42]. The trial showed significant reduction in cardiovascular events but with more incidence of major bleeding. Thus the beneficial effect of aspirin was negated by major bleeding. Similarly in the ASPREE (Aspirin in Reducing Events in the Elderly) trial, the use of low-dose aspirin as a primary prevention in older adults resulted in a significantly higher risk of major hemorrhage without any significant reduction in cardiovascular diseases as compared to placebo [72]. Keeping these facts, along with the lack of a randomized control trial in KTR, in mind, firm recommendation cannot be made for use of aspirin in primary prevention.

4.2. Secondary Prophylaxis in KTR. Patients who suffered from acute coronary syndrome or ischemic strokes are always at risk of a second cardiovascular event. Percutaneous 
intervention stabilizes acute events only. Aspirin therapy is needed for further prevention of events. The role of aspirin in reducing CVD mortality and repeat events after acute myocardial infarction was first demonstrated in the second International Study of Infarct Survival (ISIS-2) trial [73]. After ISIS-2 many trials confirmed the beneficial effects of aspirin. The Antithrombotic Trialists' Collaboration analyzed 16 trials of long-term aspirin use and found it beneficial for secondary prevention [74]. Cardiovascular disease is the leading cause of functional graft loss and it accounts for $30 \%$ of overall mortality [3]. Charytan et al. defined coronary artery disease as $>50 \%$ stenotic lesion in hemodialysis patients [75]. Other studies defined CAD as $\geq 70 \%$ stenotic lesion in pretransplant evaluation of their cohorts [76, 77]. The benefit of aspirin therapy in the setting of acute coronary syndrome and myocardial revascularization procedure has been shown across all spectra of renal dysfunction [78]. The results of studies comparing medical management vs. revascularization showed mixed findings. Studies have shown benefits of revascularization against medical management in chronic kidney disease patients only if there is $\geq 75 \%$ stenosis, triple vessel disease, or left main stem disease [79, 80]. All patients with stable coronary artery disease without obstructive lesions or those with obstructive lesions needing intervention should be on aspirin for secondary prophylaxis. KTR who have revascularization with a stent will need dual antiplatelets therapy including aspirin. Various durations for dual antiplatelets studies have been reviewed. Most studies compared either shorter (3-6 months) [31, 32, 81, 82] or longer (18-48 months) [83-85] duration of exposure. Longer duration of dual antiplatelets is associated with less stent thrombosis but with slightly more bleeding risk [84, 85]. In 2012, the American Heart Association (AHA) and American College of Cardiology (ACC) foundation published their recommendations for kidney and liver transplant recipients, which were endorsed by the American Transplant Society [30]. These guidelines recommend dual antiplatelets for 4-12 weeks for bare metal stent and $\geq 12$ months for drug eluting stents.

Newer-generation (everolimus/zotarolimus) drug eluting stents are associated with lower risk of thrombosis and coronary events than the older first-generation stents [31, 32, 86]. Keeping these facts in mind, the American College of Cardiology and American Heart Association 2016 guidelines improved the 2012 guidelines which were previously endorsed by American Society of Transplantation. The new 2016 guidelines recommend 6 months of dual antiplatelets therapy in patients treated with drug eluting stent and having stable ischemic heart disease [33]. Subsequent duration of dual antiplatelet therapy after PCI in stable coronary heart disease depends on the risk of bleeding. ACC/AHA2016 guidelines recommend continuation of dual antiplatelet beyond 1 month with bare metal stent and more than 6 months in drug eluting stent in patients who are at low risk of bleeding. Low risk patients include patients having no prior bleeding on dual antiplatelet, having no coagulopathy, and not being on oral anticoagulant [33]. In contrast, in those with high risk of bleeding (on oral anticoagulant, undergoing intracranial surgery, or developing overt bleeding), discontinuation of P2Y12 inhibitor therapy after 3 months may be reasonable [33]. The guidelines for PCI followed by stenting in the setting of acute coronary syndrome (ACS) are slightly different. In this scenario, prolonged dual antiplatelet therapy for 12 months has been found beneficial [34, 35]. Therefore, ACC/AHA2016 guidelines recommend that, for patients with acute coronary syndrome (NSTEMI/STEMI) treated with dual antiplatelets after bare metal stents or drug eluting stent insertion, thienopyridines should be given for at least 12 months [33]. The guidelines further recommend that for patients with acute coronary syndrome who has tolerated dual antiplatelets without a bleeding complication and who are not at high risk of bleeding, continuation of dual antiplatelets beyond 12 month may be reasonable. On the other extreme, for high risk ACS patients (treatment with oral anticoagulation, high risk of bleeding due to intracranial surgery, or development of overt bleeding), discontinuation of P2Y12 inhibitor after 6 months may be reasonable [33]. Patients with ACS who never underwent revascularization or fibrinolytic therapy should be treated with dual antiplatelets for at least 12 months [33, 34, 36]. For those who have tolerated dual antiplatelet therapy and are at low risk of bleeding, continuation of these beyond 12 months is beneficial [33]. For patients with ST elevated myocardial infarction, therapy should be continued for a minimum period of 14 days $[33,36]$ and ideally at least 12 months [33]. For those who tolerated dual antiplatelet therapy and are at low risk of bleeding complications, ACC/AHA recommends antiplatelets continuation beyond 12 months.

The timing of transplant surgery and other noncardiac surgeries in patients on antiplatelets therapy needs to assess risk vs. benefit of stopping antiplatelet and doing that surgery. It is wise to have a multidisciplinary meeting including cardiologist, anesthetist, surgeon, and transplant physician before taking a decision. For patients who need percutaneous intervention (PCI) and are planning for transplantation within 1 year, the 2012 guidelines [30] recommend angioplasty with bare metal stenting followed by 4-12 weeks of dual antiplatelets. For patients who have drug eluting stents needing an urgent surgery and at high risk of bleeding, guidelines recommend holding thienopyridine for 5 days and continuing aspirin preoperatively $[30,33]$. Thienopyridine may be started as early as possible after the surgery [30, 33]. The guidelines also recommend that transplantation surgery within 3 months of bare metal stent and within 12 months of drug eluting stent should not be performed [30]. Because of the lower risk of thrombosis with newer-generation stent [31, 32, 86], 2016 ACC/AHA guidelines recommend waiting for 6 months rather than 12 months in case of drug eluting stent [33]. For all elective noncardiac surgeries, it is wise to wait for 3 months in patients with bare metal stents and 6 months in patients with newer-generation drug eluting stents [33, 37-39].

The recommended daily dose for aspirin is $81 \mathrm{mg}$ (range, 75 to $100 \mathrm{mg}$ ) for prevention of secondary prophylaxis [33, 40]. Proton pump inhibitors (PPIs) are recommended in patients with dual antiplatelets with increased risk of bleeding. This includes advanced age and concomitant use of warfarin or nonsteroidal anti-inflammatory drugs (class IIa 
TABLE 3: Guidelines for use of aspirin for secondary prophylaxis.

\begin{tabular}{|c|c|}
\hline Clinical Scenarios & Recommendations \\
\hline Coronary artery disease stented with first generation bare metal stent & Dual antiplatelets for 4-12 weeks [30] \\
\hline $\begin{array}{l}\text { Coronary artery disease stented with first generation drug eluting } \\
\text { stent }\end{array}$ & Dual antiplatelet for $\geq 12$ months [30] \\
\hline Transplant surgery & $\begin{array}{c}\text { Transplant surgery within } 3 \text { months of bare metal stent and } \\
\text { within } 12 \text { months of drug eluting stent should not be } \\
\text { performed [30] }\end{array}$ \\
\hline $\begin{array}{l}\text { Stable coronary artery disease stented with newer-genration } \\
\text { (everolimus / zotarolimus) drug eluting stents }\end{array}$ & Dual antiplatelet therapy for 6 months [31-33] \\
\hline $\begin{array}{l}\text { Coronary artery disease stented with low risk of bleeding and having } \\
\text { newer-genration (everolimus / zotarolimus) drug eluting stents or } \\
\text { bare metal stent }\end{array}$ & $\begin{array}{l}\text { Guidelines recommend continuation of dual antiplatelet } \\
\text { beyond } 1 \text { month in baremetal stent and more than } 6 \text { months } \\
\text { in drug eluting stent in patients who are at low risk of } \\
\text { bleeding [33]. }\end{array}$ \\
\hline $\begin{array}{l}\text { Coronary artery disease stented with high risk of bleeding and having } \\
\text { newer-genration (everolimus / zotarolimus) drug eluting stents or } \\
\text { bare metal stent }\end{array}$ & $\begin{array}{l}\text { Discontinuation of P2Y12 inhibitor therapy after } 3 \text { months } \\
\text { may be reasonable in those with high risk of bleeding }\end{array}$ \\
\hline $\begin{array}{l}\text { Patient with acute coronary syndrome (NSTEMI / STEMI) treated } \\
\text { baremetal stent or newer generation drug eluting stent }\end{array}$ & $\begin{array}{l}\text { Dual antiplatelet should be given for atleast } 12 \text { months } \\
\qquad[33-35]\end{array}$ \\
\hline $\begin{array}{l}\text { Patients with acute coronary syndrome treated with stenting, who has } \\
\text { tollerated dual antiplatelets without a bleeding complication, and who } \\
\text { are not at high risk of bleeding }\end{array}$ & $\begin{array}{l}\text { Continuation of dual antiplatelets beyond } 12 \text { month may be } \\
\text { reasoable [33] }\end{array}$ \\
\hline $\begin{array}{l}\text { Patients with acute coronary syndrome treated with stenting and at } \\
\text { high risk of bleeding }\end{array}$ & $\begin{array}{c}\text { Discontinuation of P2Y12 inhibitor after } 6 \text { months may be } \\
\text { reasonable [33] }\end{array}$ \\
\hline $\begin{array}{l}\text { Patients with ACS who never underwent revascularization or } \\
\text { fibrinolytic therapy }\end{array}$ & $\begin{array}{l}\text { They should be treated with dual antiplatelets for at least } 12 \\
\text { months }[33,34,36] \text {. }\end{array}$ \\
\hline ST elevated myocardial infarction & $\begin{array}{l}\text { Should be continued on dual antiplatlet for a minimum } \\
\text { period of } 14 \text { days }[33,36] \text { and ideally at least } 12 \text { months }[33] \text {. }\end{array}$ \\
\hline Patients planning for transplantation in one year and needing PCI & $\begin{array}{l}\text { Angioplasty with bare metal stenting followed by } 4-12 \text { weeks } \\
\text { of dual antiplatelets [30]. }\end{array}$ \\
\hline KTR on dual antiplatelets needing emergency surgery & $\begin{array}{c}\text { Hold thienopyridine for } 5 \text { days and continuing aspirin } \\
\text { preoperatively [30, 33].Thienopyridine, may be started as } \\
\text { early as possible after the surgery }[30,33] \text {. }\end{array}$ \\
\hline $\begin{array}{l}\text { Waiting time for kidney transplantation and other elective surgery } \\
\text { after PCI }\end{array}$ & $\begin{array}{l}\text { Wait for } 3 \text { months in case of bare metal stenting and } 6 \\
\text { months for drug eluting stenting }[33,37-39] \text {. }\end{array}$ \\
\hline Dose of aspirin & $\begin{array}{l}\text { The recommended dialy dose for aspirin is } 81 \mathrm{mg} \text { (range, } 75 \\
\text { to } 100 \mathrm{mg} \text { ) for prevention of secondary prophylaxis }[33,40]\end{array}$ \\
\hline Proton pumpinhibitors & $\begin{array}{l}\text { Proton pump inhibitors (PPIs) are recommended in patients } \\
\text { with dual antiplatelets with increased risk of bleeding. This } \\
\text { includes advance age, concomitant use of warfarin or non } \\
\text { steroidal antiinflammatory drugs (class } 2 \mathrm{a} \text { evidence). Routine } \\
\text { use of PPIs in patients at low risk of bleeding is not } \\
\text { recommended (class III, no benefits) [33]. }\end{array}$ \\
\hline
\end{tabular}

evidence) [33]. Routine use of PPIs for patients at low risk of bleeding is not recommended (class III, no benefits). Since transplant patients are concurrently using steroids, it is wise to use PPIs for prevention of gastrointestinal bleeding. Table 3 is showing various recommendations for use of aspirin in secondary prophylaxis.

\section{Way Forward}

While starting aspirin, one has to keep in mind risks versus benefits. The benefits of aspirin can be offset by the associated risk of bleeding. This is of particular concern in KTR, who are being considered for primary prevention with aspirin.
KDIGO 2009 practice guidelines for prevention of cardiovascular events in KTR recommend aspirin in patients with diabetes or cardiovascular disease. However, this is based on very poor quality of evidence [71]. The recent trial by the ASCEND Study Collaborative Group found that aspirin use prevented serious vascular events in diabetics. However, the absolute benefits were largely counterbalanced by the bleeding hazard [42]. Similarly the elderly population who received aspirin for primary prevention in recent APREE trial has more bleeding without any benefit [72]. However, both of these studies were done in the general population. KTR are different in terms of cardiovascular risk. Other than traditional risk factors, KTR have many others. Furthermore, cardiovascular events are 
among the leading causes of functional graft loss. Therefore, there is an urgent need for a randomized control trial on aspirin for its use in primary prevention. Until the evidence is available, it cannot be recommended for primary prevention of cardiovascular events at the moment. On the other hand, aspirin should be used routinely for secondary prophylaxis in KTR. Aspirin has not been shown to be associated with nephrotoxicity in many studies [8-21]. However, like in the general population, bleeding is a genuine concern in KTR. ACC/AHA recommends the assessment of the risk of bleeding using HAS-BLED score (Hypertension, Abnormal renal/liver function, Stroke, Bleeding history or predisposition, Labile INR, Elderly, Drugs/alcohol) [33]. Most of these risk factors are present in chronic kidney disease patients and KTR. A new score for dual antiplatelets called DAPT (Dual Antiplatelet Therapy) Score has also been developed [87]. This score uses various factors including various age ranges, current smoking status, diabetes mellitus, myocardial infarction at presentation, prior PCI or prior myocardial infarction, stent diameter $<3 \mathrm{~mm}$, paclitaxel eluting stent, congestive heart failure or left ventricular ejection fraction $<30 \%$, and saphenous vein graft percutaneous intervention. This score helps with the decision whether to give antiplatelet for a long duration or not. Dual antiplatelet may be suitable in those with DAPT Score greater than 2, as use of dual antiplatelet is associated with less risk of ischemic events and less bleeding risk. On the other hand, with a low DAPT Score of $<2$, prolonged use of dual antiplatelets causes increased risk of bleeding without reduction in ischemic events.

\section{Conclusion}

Aspirin should be used in established coronary artery disease for secondary prevention. Low-dose aspirin has not been shown to cause nephrotoxicity. The beneficial effects of aspirin are offset by high risk of major bleeding in primary prevention in the general population. Due to lack of evidence at the moment, it cannot be recommended for primary prevention of cardiovascular events in KTR. The risk of bleeding should be assessed in all recipients before starting aspirin. KTR have many risk factors other than the traditional risk factors. There is a need for development of a cardiovascular risk prediction score targeting the kidney transplant population. A randomized control trial is also needed to assess the beneficial effect of primary prophylaxis with aspirin in the kidney transplant population. The final decision on using aspirin should be made after balancing the specific characteristics of each patient taken into account the patient's risk for bleeding and the concomitant pathologies in each case.

\section{Conflicts of Interest}

The authors declare that they have no conflicts of interest.

\section{References}

[1] Health Resources and Services Administration, "Organ procurement and transplant network database," 2013, http://optn .transplant.hrsa.gov/.
[2] B. L. Kasiske, J. R. Maclean, and J. J. Snyder, "Acute myocardial infarction and kidney transplantation," Journal of the American Society of Nephrology, vol. 17, no. 3, pp. 900-907, 2006.

[3] V. Ramanathan, S. Goral, B. Tanriover et al., "Screening asymptomatic diabetic patients for coronary artery disease prior to renal transplantation," Transplantation, vol. 79, no. 10, pp. 1453$1458,2005$.

[4] K. Schrör, "Aspirin and platelets: the antiplatelet action of aspirin and its role in thrombosis treatment and prophylaxis," Seminars in Thrombosis and Hemostasis, vol. 23, no. 4, pp. 349356, 1997.

[5] M. Morlans, J. Laporte, X. Vidal, D. Cabeza, and P. Stolley, "Endstage renal disease and non-narcotic analgesics: a case-control study," British Journal of Clinical Pharmacology, vol. 30, no. 5, pp. 717-723, 1990.

[6] C. M. Fored, E. Ejerblad, P. Lindblad et al., "Acetaminophen, aspirin, and chronic renal failure," The New England Journal of Medicine, vol. 345, no. 25, pp. 1801-1808, 2001.

[7] L. Ibanez, M. Morlans, X. Vidal, M. J. Martinez, and J.-R. Laporte, "Case-control study of regular analgesic and nonsteroidal anti-inflammatory use and end-stage renal disease," Kidney International, vol. 67, no. 6, pp. 2393-2398, 2005.

[8] T. V. Perneger, P. K. Whelton, and M. J. Klag, "Risk of kidney failure associated with the use of acetaminophen, aspirin, and nonsteroidal antiinflammatory drugs," The New England Journal of Medicine, vol. 331, no. 25, pp. 1675-1679, 1994.

[9] D. P. Sandler, J. C. Smith, C. R. Weinberg et al., "Analgesic use and chronic renal disease," The New England Journal of Medicine, vol. 320, no. 19, pp. 1238-1243, 1989.

[10] T. Kurth, R. J. Glynn, A. M. Walker et al., "Analgesic use and change in kidney function in apparently healthy men," American Journal of Kidney Diseases, vol. 42, no. 2, pp. 234-244, 2003.

[11] K. M. Rexrode, J. E. Buring, R. J. Glynn, M. J. Stampfer, L. D. Youngman, and J. M. Gaziano, "Analgesic use and renal function in men," Journal of the American Medical Association, vol. 286, no. 3, pp. 315-321, 2001.

[12] L. Y. Agodoa, M. E. Francis, and P. W. Eggers, "Association of analgesic use with prevalence of albuminuria and reduced GFR in US adults," American Journal of Kidney Diseases, vol. 51, no. 4, pp. 573-583, 2008.

[13] G. C. Curhan, E. L. Knight, B. Rosner, S. E. Hankinson, and M. J. Stampfer, "Lifetime nonnarcotic analgesic use and decline in renal function in women," JAMA Internal Medicine, vol. 164, no. 14, pp. 1519-1524, 2004.

[14] S. Okada, T. Morimoto, H. Ogawa et al., "Is long-term low-dose aspirin therapy associated with renal dysfunction in patients with type 2 diabetes? JPAD2 cohort study," PLoS ONE, vol. 11, no. 1, Article ID e0147635, 2016.

[15] H. P. Hansen, P. H. Gæde, B. R. Jensen, and H.-H. Parving, "Lack of impact of low-dose acetylsalicylic acid on kidney function in type 1 diabetic patients with microalbuminuria," Diabetes Care, vol. 23, no. 12, pp. 1742-1745, 2000.

[16] P. Gæde, H. P. Hansen, H.-H. Parving, and O. Pedersen, "Impact of low-dose acetylsalicylic acid on kidney function in type 2 diabetic patients with elevated urinary albumin excretion rate," Nephrology Dialysis Transplantation, vol. 18, no. 3, pp. 539-542, 2003.

[17] A. H. Hopper, H. Tindall, and J. A. Davies, "Administration of aspirin-dipyridamole reduces proteinuria in diabetic nephropathy," Nephrology Dialysis Transplantation, vol. 4, no. 2, pp. 140143, 1989. 
[18] W. Grotz, S. Siebig, M. Olschewski, C. W. Strey, and K. Peter, "Low-dose aspirin therapy is associated with improved allograft function and prolonged allograft survival after kidney transplantation," Transplantation, vol. 77, no. 12, pp. 1848-1853, 2004.

[19] W. Cheungpasitporn, C. Thongprayoon, D. G. Mitema et al., "The effect of aspirin on kidney allograft outcomes; a short review to current studies," Journal of Nephropathology, vol. 6, no. 3, pp. 110-117, 2017.

[20] H. Ali, A. Shaaban, A. Murtaza, L. Howell, and A. Ahmed, "Effect of long-term, low-dose aspirin therapy on renal graft function," Experimental and Clinical Transplantation, vol. 15, no. 4, pp. 400-440, 2015.

[21] G. J. Murphy, R. Taha, D. C. Windmill, M. Metcalfe, and M. L. Nicholson, "Influence of aspirin on early allograft thrombosis and chronic allograft nephropathy following renal transplantation," British Journal of Surgery, vol. 88, no. 2, pp. 261-266, 2001.

[22] A. J. Robertson, V. Nargund, D. W. R. Gray, and P. J. Morris, "Low dose aspirin as prophylaxis against renal-vein thrompbosis in renal-transplant recipients," Nephrology Dialysis Transplantation, vol. 15, no. 11, pp. 1865-1868, 2000.

[23] L. D. Hachem, A. Ghanekar, M. Selzner, O. Famure, Y. Li, and S. J. Kim, "Postoperative surgical-site hemorrhage after kidney transplantation: incidence, risk factors, and outcomes," Transplant International, vol. 30, no. 5, pp. 474-483, 2017.

[24] F. Weng, A. Athavale, K. Hussain, K. Tibaldi, and G. Rogal, "Complications of dual antiplatelet therapy among recipients of kidney transplants," American Journal of Transplantation, vol. 16, supplement 3, 2016.

[25] P. D. Bailey, H. Ali, M. Lubetzky, and L. K. Kayler, "Outcomes of kidney transplant recipients on dual antiplatelet therapy," Austin Journal of Nephrology and Hypertension, vol. 2, no. 3, p. 1040, 2015.

[26] M. A. Shullo, M. L. Rose, C. Vivas et al., "Hemorrhagic complications of enoxaparin and aspirin in patients with kidney transplants," Pharmacotherapy, vol. 22, no. 2, pp. 184-187, 2002.

[27] T. D. Atwell, R. L. Smith, G. K. Hesley et al., "Incidence of bleeding after 15,181 percutaneous biopsies and the role of aspirin," American Journal of Roentgenology, vol. 194, no. 3, pp. 784-789, 2010.

[28] F. I. Baffour, L. J. Hickson, M. D. Stegall et al., "Effects of aspirin therapy on ultrasound-guided renal allograft biopsy bleeding complications," Journal of Vascular and Interventional Radiology, vol. 28, no. 2, pp. 188-194, 2017.

[29] J. S. Lees, E. P. McQuarrie, N. Mordi, C. C. Geddes, J. G. Fox, and B. Mackinnon, "Risk factors for bleeding complications after nephrologist-performed native renal biopsy," Clinical Kidney Journal, vol. 10, no. 4, pp. 573-577, 2017.

[30] K. L. Lentine, S. P. Costa, M. R. Weir et al., "Cardiac disease evaluation and management among kidney and liver transplantation candidates: A scientific statement from the american heart association and the American college of cardiology foundation," Circulation, vol. 126, no. 5, pp. 617-663, 2012.

[31] A. Colombo, A. Chieffo, A. Frasheri et al., "Second-generation drug-eluting stent implantation followed by 6-Versus 12-month dual antiplatelet therapy," Journal of the American College of Cardiology, vol. 64, no. 20, pp. 2086-2097, 2014.

[32] H.-C. Gwon, J.-Y. Hahn, K. W. Park et al., "Six-month versus 12-month dual antiplatelet therapy after implantation of drugeluting stents: The efficacy of xience/promus versus cypher to reduce late loss after stenting (EXCELLENT) randomized, multicenter study," Circulation, vol. 125, no. 3, pp. 505-513, 2012.
[33] G. N. Levine, E. R. Bates, J. A. Bittl et al., “2016 ACC/AHA guideline focused update on duration of dual antiplatelet therapy in patients with coronary artery disease: A report of the American college of cardiology/American heart association task force on clinical practice guidelines," The Journal of Thoracic and Cardiovascular Surgery, vol. 152, no. 5, pp. 1243-1275, 2016.

[34] S. Yusuf, F. Zhao, S. R. Mehta, S. Chrolavicius, G. Tognoni, and K. K. Fox, "Effects of clopidogrel in addition to aspirin in patients with acute coronary syndromes without ST-segment elevation," The New England Journal of Medicine, vol. 345, no. 7, pp. 494-502, 2001.

[35] M. S. Sabatine, C. P. Cannon, C. M. Gibson et al., "Effect of clopidogrel pretreatment before percutaneous coronary intervention in patients with ST-elevation myocardial infarction treated with fibrinolytics: The PCI-CLARITY study," Journal of the American Medical Association, vol. 294, no. 10, pp. 1224-1232, 2005.

[36] Z. M. Chen, L. X. Jiang, Y. P. Chen et al., "Addition of clopidogrel to aspirin in 45852 patients with acute myocardial infarction: randomised placebo-controlled trial," The Lancet, vol. 366, no. 9497, pp. 1607-1621, 2005.

[37] G. L. Kaluza, J. Joseph, J. R. Lee, M. E. Raizner, and A. E. Raizner, "Catastrophic outcomes of noncardiac surgery soon after coronary stenting," Journal of the American College of Cardiology, vol. 35, no. 5, pp. 1288-1294, 2000.

[38] G. A. Nuttall, M. J. Brown, J. W. Stombaugh et al., “Time and cardiac risk of surgery after bare-metal stent percutaneous coronary intervention," Anesthesiology, vol. 109, no. 4, pp. 588595, 2008.

[39] S. Wilson, P. Fasseas, J. Orford et al., "Clinical outcome of patients undergoing non-cardiac surgery in the two months following coronary stenting," JACC: Journal of the American College of Cardiology, vol. 42, pp. 234-240, 2003.

[40] S. S. Jolly, J. Pogue, K. Haladyn et al., "Effects of aspirin dose on ischaemic events and bleeding after percutaneous coronary intervention: insights from the PCI-CURE study," European Heart Journal, vol. 30, no. 8, pp. 900-907, 2008.

[41] P. C. Elwood, G. Morgan, J. Galante et al., "Systematic review and meta-analysis of randomised trials to ascertain fatal gastrointestinal bleeding events attributable to preventive low-dose aspirin: no evidence of increased risk," PLoS ONE, vol. 11, no. 11, Article ID e0166166, 2016.

[42] ASCEND Study Collaborative Group, "Effects of aspirin for primary prevention in persons with diabetes mellitus," The New England Journal of Medicine, vol. 379, no. 16, pp. 1529-1539, 2018.

[43] C. Matsumoto, S. J. Swanson, L. Y. Agodoa, K. C. Holtzmuller, and K. C. Abbott, "Hospitalized gastrointestinal bleeding and procedures after renal transplantation in the United States," Journal of Nephrology, vol. 16, no. 1, pp. 49-56, 2003.

[44] M. M. Sood, A. X. Garg, S. E. Bota et al., "Risk of major hemorrhage after kidney transplantation," American Journal of Nephrology, vol. 41, no. 1, pp. 73-80, 2015.

[45] P. W. F. Wilson, R. B. D’Agostino, D. Levy, A. M. Belanger, H. Silbershatz, and W. B. Kannel, "Prediction of coronary heart disease using risk factor categories," Circulation, vol. 97, no. 18, pp. 1837-1847, 1998.

[46] P. M. Ridker, J. E. Buring, N. Rifai, and N. R. Cook, "Development and validation of improved algorithms for the assessment of global cardiovascular risk in women: the Reynolds risk score," The Journal of the American Medical Association, vol. 297, no. 6, pp. 611-619, 2007.

[47] R. M. Conroy, K. Pyörälä, A. P. Fitzgerald et al., "Estimation of ten-year risk of fatal cardiovascular disease in Europe: the 
SCORE project," European Heart Journal, vol. 24, no. 11, pp. 9871003, 2003.

[48] G. Assmann, P. Cullen, and H. Schulte, "Simple scoring scheme for calculating the risk of acute coronary events based on the 10-year follow-up of the Prospective Cardiovascular Münster (PROCAM) study," Circulation, vol. 105, no. 3, pp. 310-315, 2002.

[49] J. Hippisley-Cox, C. Coupland, Y. Vinogradova, J. Robson, M. May, and P. Brindle, "Derivation and validation of QRISK, a new cardiovascular disease risk score for the United Kingdom: prospective open cohort study," British Medical Journal, vol. 335, no. 7611, pp. 136-141, 2007.

[50] G. S. Collins and D. G. Altman, "An independent and external validation of QRISK2 cardiovascular disease risk score: a prospective open cohort study," BMJ, vol. 340, no. 2, pp. c2442c2442, 2010.

[51] K. Bibbins-Domingo, D. C. Grossman, S. J. Curry et al., "Aspirin use for the primary prevention of cardiovascular disease and colorectal cancer: U.S. preventive services task force recommendation statement," Annals of Internal Medicine, vol. 164, no. 12, pp. 836-845, 2016.

[52] C. Rigatto, P. Parfrey, R. Foley, C. Negrijn, C. Tribula, and J. Jeffery, "Congestive heart failure in renal transplant recipients: Risk factors, outcomes, and relationship with ischemic heart disease," Journal of the American Society of Nephrology, vol. 13, no. 4, pp. 1084-1090, 2002.

[53] B. K. Krämer, C. Zülke, M. C. Kammerl et al., "Cardiovascular risk factors and estimated risk for $\mathrm{CAD}$ in a randomized trial comparing calcineurin inhibitors in renal transplantation," American Journal of Transplantation, vol. 3, no. 8, pp. 982-987, 2003.

[54] H.-U. Meier-Kriesche, B. J. Steffen, A. M. Hochberg et al., "Mycophenolate mofetil versus azathioprine therapy is associated with a significant protection against long-term renal allograft function deterioration," Transplantation, vol. 75, no. 8, pp. 1341-1346, 2003.

[55] D. Ducloux, G. Motte, and Z. A. Massy, "Hyperhomocyst(e)inemia as a risk factor after renal transplantation," Annals of Transplantation : Quarterly of the Polish Transplantation Society, vol. 6, no. 4, pp. 40-42, 2001.

[56] D. Ducloux, A. Kazory, and J.-M. Chalopin, "Predicting coronary heart disease in renal transplant recipients: A prospective study," Kidney International, vol. 66, no. 1, pp. 441-447, 2004.

[57] S. A. Silver, M. Huang, M. M. Nash, and G. V. R. Prasad, "Framingham risk score and novel cardiovascular risk factors underpredict major adverse cardiac events in kidney transplant recipients," Transplantation, vol. 92, no. 2, pp. 183-189, 2011.

[58] Z. Heleniak, K. Komorowska-Jagielska, and A. Dębska-Ślizień, "Assessment of cardiovascular risk in renal transplant recipients: preliminary results," Transplantation Proceedings, vol. 50, no. 6, pp. 1813-1817, 2018.

[59] I. Soveri, I. Holme, H. Holdaas, K. Budde, A. G. Jardine, and B. Fellström, "A cardiovascular risk calculator for renal transplant recipients," Transplantation, vol. 94, no. 1, pp. 57-62, 2012.

[60] H. Mansell, S. A. Stewart, and A. Shoker, "Validity of cardiovascular risk prediction models in kidney transplant recipients," The Scientific World Journal, vol. 2014, Article ID 750579, 13 pages, 2014.

[61] D. C. Goff, D. M. Lloyd-Jones, G. Bennett et al., "2013 ACC/AHA guideline on the assessment of cardiovascular risk: a report of the American college of cardiology/American heart association task force on practice guidelines," Journal of the
American College of Cardiology, vol. 63, no. 25, pp. 2935-2959, 2014.

[62] American Diabetes Association, "Cardiovascular disease and risk management: standards of medical care in diabetes," Diabetes Care, vol. 41, supplement 1, pp. S86-S104, 2018.

[63] A. D. Bell, A. Roussin, R. Cartier et al., "The use of antiplatelet therapy in the outpatient setting: canadian cardiovascular society guidelines executive summary," Canadian Journal of Cardiology, vol. 27, no. 2, pp. 208-221, 2011.

[64] International Asprin Foundation, "Summary of UK guidelines for aspirin," 2018, https://www.aspirin-foundation .com/guidelines/uk-guidelines-aspirin/.

[65] C. S. Fox, P. Muntner, A. Y. Chen et al., "Use of evidence-based therapies in short-term outcomes of ST-segment elevation myocardial infarction and non-ST-segment elevation myocardial infarction in patients with chronic kidney disease: a report from the national cardiovascular data acute coronary treatment and intervention outcomes network registry," Circulation, vol. 121, no. 3, pp. 357-365, 2010.

[66] A. K. Berger, S. Duval, and H. M. Krumholz, "Aspirin, betablocker, and angiotensin-converting enzyme inhibitor therapy in patients with end-stage renal disease and an acute myocardial infarction," Journal of the American College of Cardiology, vol. 42, no. 2, pp. 201-208, 2003.

[67] M. J. Jardine, T. Ninomiya, V. Perkovic et al., "Aspirin is beneficial in hypertensive patients with chronic kidney disease: A post-hoc subgroup analysis of a randomized controlled trial," Journal of the American College of Cardiology, vol. 56, no. 12, pp. 956-965, 2010.

[68] P. A. McCullough, K. R. Sandberg, S. Borzak, M. P. Hudson, M. Garg, and H. J. Manley, "Benefits of aspirin and beta-blockade after myocardial infarction in patients with chronic kidney disease," American Heart Journal, vol. 144, no. 2, pp. 226-232, 2002.

[69] A. Sciahbasi, R. Arcieri, M. Quarto et al., "Impact of chronic aspirin and statin therapy on presentation of patients with acute myocardial infarction and impaired renal function," Preventive Cardiology, vol. 13, no. 1, pp. 18-22, 2010.

[70] T. Dad, H. Tighiouart, A. Joseph et al., "Aspirin use and incident cardiovascular disease, kidney failure, and death in stable kidney transplant recipients: a post hoc analysis of the folic acid for vascular outcome reduction in transplantation (FAVORIT) trial," American Journal of Kidney Diseases, vol. 68, no. 2, pp. 277-286, 2016.

[71] B. L. Kasiske, M. G. Zeier, J. R. Chapman et al., "KDIGO clinical practice guideline for the care of kidney transplant recipients: a summary," Kidney International, vol. 77, no. 4, pp. 299-311, 2010.

[72] J. J. McNeil, R. Wolfe, R. L. Woods et al., "Effect of aspirin on cardiovascular events and bleeding in the healthy elderly," The New England Journal of Medicine, vol. 379, no. 16, pp. 1509-1518, 2018.

[73] ISIS-2 (Second International Study of Infarct Survival) Collaborative Group, "Randomised trial of intravenous streptokinase, oral aspirin, both, or neither among 17,187 cases of suspected acute myocardial infarction: ISIS-2," The Lancet, vol. 2, no. 8607, pp. 349-360, 1988.

[74] Antithrombotic Trialists' Collaboration, "Collaborative metaanalysis of randomised trials of antiplatelet therapy for prevention of death, myocardial infarction, and stroke in high risk patients," British Medical Journal, vol. 324, no. 7329, pp. 71-86, 2002. 
[75] D. Charytan, R. E. Kuntz, L. Mauri, and C. DeFilippi, "Distribution of coronary artery disease and relation to mortality in asymptomatic hemodialysis patients," American Journal of Kidney Diseases, vol. 49, no. 3, pp. 409-416, 2007.

[76] J. J. G. De Lima, E. Sabbaga, M. L. C. Vieira et al., "Coronary angiography is the best predictor of events in renal transplant candidates compared with noninvasive testing," Hypertension, vol. 42, no. 3, pp. 263-268, 2003.

[77] L. H. W. Gowdak, F. J. De Paula, L. A. M. César et al., "Screening for significant coronary artery disease in high-risk renal transplant candidates," Coronary Artery Disease, vol. 18, no. 7, pp. 553-558, 2007.

[78] R. S. Wright, G. S. Reeder, C. A. Herzog et al., "Acute myocardial infarction and renal dysfunction: A high-risk combination," Annals of Internal Medicine, vol. 137, no. 7, pp. 563-570, 2002.

[79] C. L. Manske, Y. Wang, T. Rector, R. F. Wilson, and C. W. White, "Coronary revascularisation in insulin-dependent diabetic patients with chronic renal failure," The Lancet, vol. 340, no. 8826, pp. 998-1002, 1992.

[80] N. Kumar, C. S. R. Baker, K. Chan et al., "Cardiac survival after pre-emptive coronary angiography in transplant patients and those awaiting transplantation," Clinical Journal of the American Society of Nephrology, vol. 6, no. 8, pp. 1912-1919, 2011.

[81] B.-K. Kim, M.-K. Hong, D.-H. Shin et al., "A new strategy for discontinuation of dual antiplatelet therapy: real safety and efficacy of 3 months dual antiplatelet therapy following endeavor zotarolimus-eluting stent implantation," Journal of the American College of Cardiology, vol. 60, pp. 1340-1348, 2012.

[82] F. Feres, R. A. Costa, A. Abizaid et al., “Three vs twelve months of dual antiplatelet therapy after zotarolimus-eluting stents: The OPTIMIZE randomized trial," Journal of the American Medical Association, vol. 310, no. 23, pp. 2510-2522, 2013.

[83] C. W. Lee, J.-M. Ahn, D.-W. Park et al., "Optimal duration of dual antiplatelet therapy after drug-eluting stent implantation: a randomized, controlled trial," Circulation, vol. 129, pp. 304312, 2014.

[84] M. Gilard, P. Barragan, A. A. L. Noryani et al., "6- versus 24month dual antiplatelet therapy after implantation of drugeluting stents in patients nonresistant to aspirin: the randomized, multicenter ITALIC trial," JACC: Journal of the American College of Cardiology, vol. 65, pp. 777-786, 2015.

[85] J. B. Hermiller, M. W. Krucoff, D. J. Kereiakes et al., "Benefits and risks of extended dual antiplatelet therapy after everolimuseluting stents," JACC: Cardiovascular Interventions, vol. 9, no. 2, pp. 138-147, 2016.

[86] G. Giustino, U. Baber, S. Sartori et al., "Duration of dual antiplatelet therapy after drug-eluting stent implantation: A systematic review and meta-analysis of randomized controlled trials," Journal of the American College of Cardiology, vol. 65, no. 13, pp. 1298-1310, 2015.

[87] R. W. Yeh, E. A. Secemsky, D. J. Kereiakes et al., "Development and validation of a prediction rule for benefit and harm of dual antiplatelet therapy beyond 1 year after percutaneous coronary intervention," Journal of the American Medical Association, vol. 315, no. 16, pp. 1735-1749, 2016. 


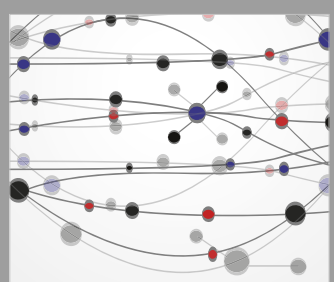

The Scientific World Journal
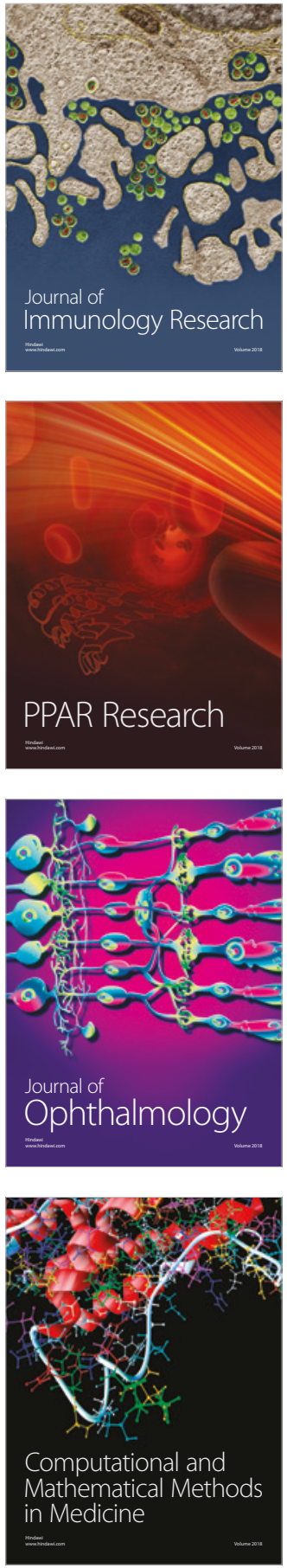

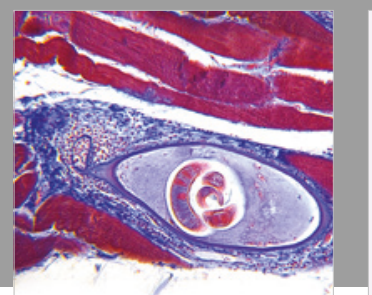

Gastroenterology Research and Practice

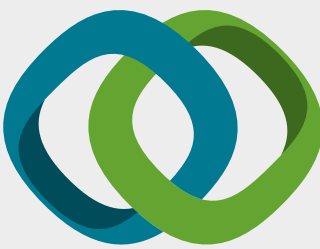

\section{Hindawi}

Submit your manuscripts at

www.hindawi.com
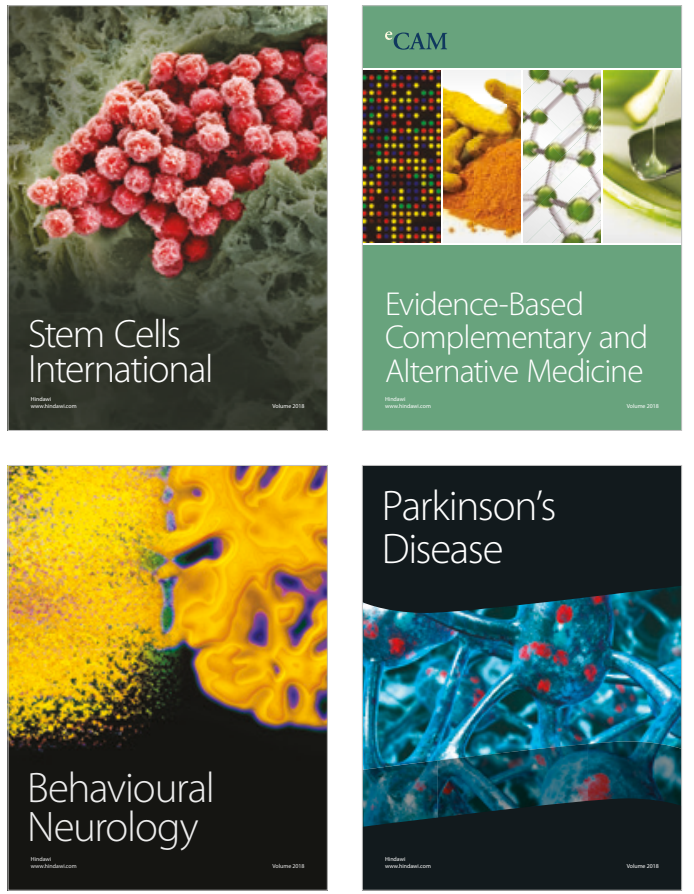

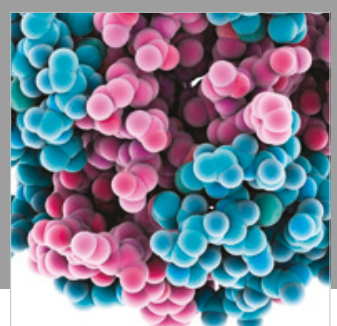

ournal of

Diabetes Research

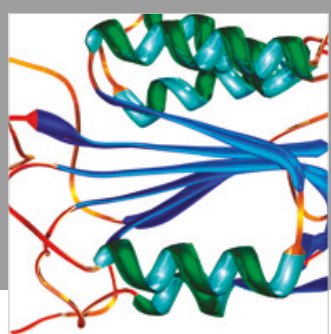

Disease Markers
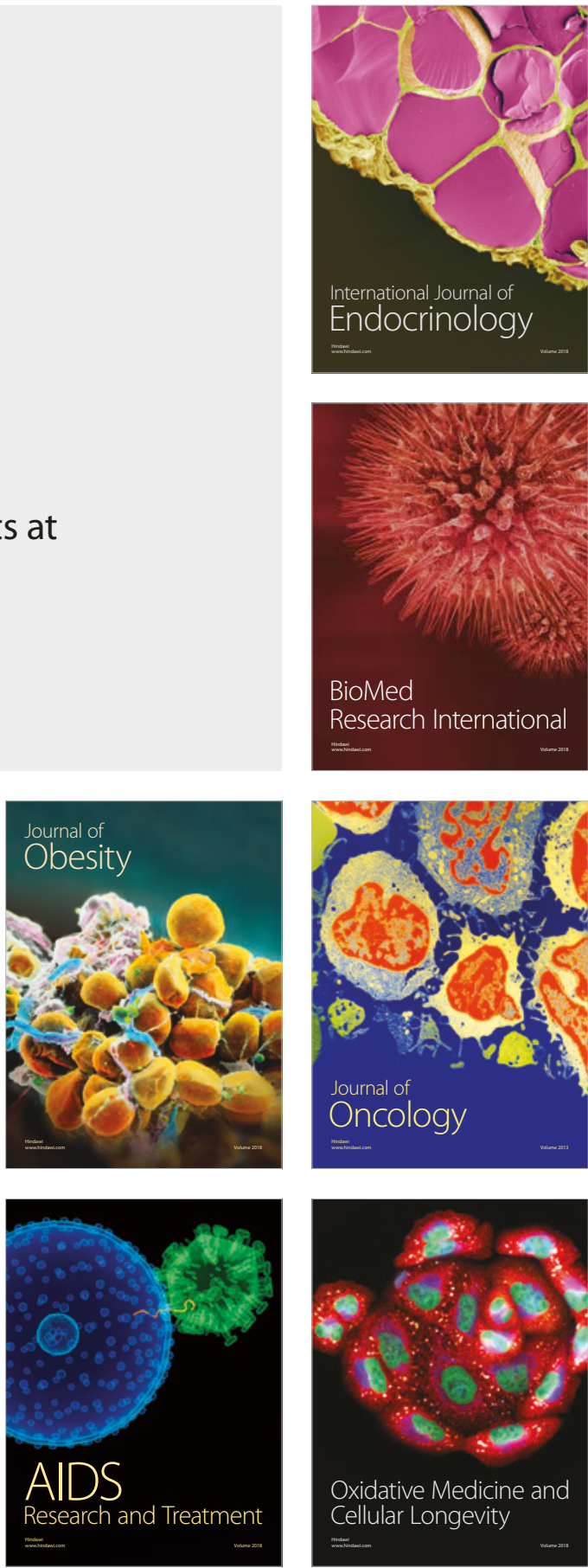